Illinois State University

ISU ReD: Research and eData

Theses and Dissertations

4-25-2014

Cultural Identity and Heritage Language Learners

Lydia Reitz

Illinois State University, lydia.reitz@gmail.com

Follow this and additional works at: https://ir.library.illinoisstate.edu/etd

Part of the Bilingual, Multilingual, and Multicultural Education Commons, and the Race, Ethnicity and Post-Colonial Studies Commons

Recommended Citation

Reitz, Lydia, "Cultural Identity and Heritage Language Learners" (2014). Theses and Dissertations. 182. https://ir.library.illinoisstate.edu/etd/182

This Thesis is brought to you for free and open access by ISU ReD: Research and eData. It has been accepted for inclusion in Theses and Dissertations by an authorized administrator of ISU ReD: Research and eData. For more information, please contact ISUReD@ilstu.edu. 


\title{
CULTURAL IDENTITY AND HERITAGE LANGUAGE LEARNERS
}

\author{
Lydia S. Reitz
}

48 Pages

August 2014

College-aged heritage language learners (HLLS) are becoming more prevalent in the foreign language $(F L)$ classroom. For the purposes of this exploratory study, HLL is defined as an individual who was born in the United States of parents from a Spanishspeaking country (Valdés, 2001). These individuals have an almost comprehensive speaking proficiency and various ranges of grammatical dominance of Spanish (Valdés, 2001). HLLs' cultural identity and its influences on classroom motivation, and how it influences motivation of HLLs, are in need of investigation. The rising number of immigrants from Spanish-speaking countries necessitates that this group of students and how they fit in the FL classroom be researched. Twenty-two HLLs', who are enrolled in an FL course, cultural identity and motivations to learn Spanish are examined using a survey based on Noels, Pelletier, Clement, and Vallerand's (2003). This study found that cultural identity may have as much of an influence on classroom motivation as previously thought by researchers like Berardi-Wiltshire (2012), however, the measure of cultural identity may not reflect the entirety of each participant's connection to the heritage culture. 


\title{
CULTURAL IDENTITY AND HERITAGE LANGUAGE LEARNERS
}

\author{
LYDIA S. REITZ
}

\author{
A Thesis Submitted in Partial \\ Fulfillment of the Requirements \\ for the Degree of \\ MASTER OF ART \\ Department of Languages, Literatures, and Cultures \\ ILLINOIS STATE UNIVERSITY
}




\title{
CULTURAL IDENTITY AND HERITAGE LANGUAGE LEARNERS
}

\author{
LYDIA S. REITZ
}

COMMITTEE MEMBERS:

Susan Hildebrandt, Chair

Montserrat Mir

Rachel Shively 


\section{CONTENTS}

Page

CONTENTS

i

TABLES iii

FIGURES iv

CHAPTER

I. THE PROBLEM AND ITS BACKGROUND 1

II. REVIEW OF RELATED LITERATURE

Cultural Identity $\quad 5$

$\begin{array}{ll}\text { Motivation } & 7\end{array}$

Self-Determination Theory $\quad 9$

Motivation and Language Learning 10

Identity and Motivation 13

$\begin{array}{ll}\text { Instructional Methods } & 15\end{array}$

$\begin{array}{ll}\text { Conclusion } & 18\end{array}$

$\begin{array}{ll}\text { III. METHODOLOGY } & 19\end{array}$

Participants $\quad 19$

$\begin{array}{ll}\text { Materials } & 19\end{array}$

$\begin{array}{ll}\text { Procedures } & 20\end{array}$

$\begin{array}{ll}\text { IV. RESULTS } & 22\end{array}$

V. DISCUSSION 33

VI. CONCLUSIONS AND RECOMMENDATIONS 37

$\begin{array}{ll}\text { REFERENCES } & 40\end{array}$ 
APPENDIX A: $\quad$ Informed Consent (for survey)

APPENDIX B: $\quad$ Loyalty Scale for Participants and Parents $\quad 44$

APPENDIX C: $\quad$ Self-Determination Identification Survey 46 


\section{TABLES}

Table

Page

1. Interaction between Participants and Peers

2. Peer Language 25

3. Family Language 26

4. Frequency of Each Item with Degrees of Agreement 28

5. Frequency of Each Item with Degree of Agreement for North American Participants

6. Frequency of Each Item with Degree of Agreement for Hispanic Participants 30

7. Descriptive Statistics of Self-identified Groups by Motivational Factors 


\section{FIGURES}

\section{Figure}

Page

1. Cultural Loyalty 


\section{CHAPTER I}

\section{THE PROBLEM AND ITS BACKGROUND}

Classrooms are made up of various types of learners and unique individuals and part of the teacher's role is to teach each individual while keeping these differences and abilities in mind. While various research exists about the individuals with differences that make up a classroom, more research exists about heritage language learners (HLLs) that are becoming more prevalent in the foreign language (FL) classroom (Berardi-Wiltshire, 2012; Castillo, 2003; Valdés, 2001). While this group and its cultural identity have been studied within the FL classroom (Berardi-Wiltshire, 2012), there are still other areas of study that need to be addressed. Cultural identity and how it may or may not have the ability to influence motivation in the classroom are two of those necessary areas of study.

With the rising number of immigrants from Spanish-speaking countries, it is imperative to research this group of students and how they fit in the FL classroom. In recent years, it has become necessary to include Spanish HLLs as a group of interest within the classroom since $15.1 \%$ of the United States population identifies as Hispanic (Central Intelligence Agency, 2010). Along with the rising Hispanic population, there are also language requirements for many students in American high schools. According to The Nuffield Foundation (2000), many times FL classes are required for graduation 
from either high school or college, but many students stop after this requirement is fulfilled. These requirements need to be reexamined, not only with HLLs in mind, but also how the cultural identity can possibly encourage students to move past just the basic requirements. Two types of Spanish classrooms have generally been available to Spanish HLLs: the type that addresses the needs of these HLLs without the influence of other students who lack heritage ties to the language and the type that encourages the two groups in the same classroom to promote authentic communication and cultural insights. The latter, in this context, is an inclusive setting. One possibility can be to separate groups of students with differences or certain abilities, instead of figuring out how to include them in the classroom with non-HLL students. It is vital to study the language learning motivation of HLLs, so it can aid educators in gaining insight to these students' needs. This newfound information can reform outdated thoughts and move FL education forward, producing a new generation of motivated and integrated individuals who can succeed in a multicultural and globalized world.

Motivation is the driving force behind the behavior of an individual. As such, it is particularly important when completing any task and, more specifically, learning a language. Because the cultural background and makeup of every individual is different, views on language can be different as well. One specific group that will be discussed in relation to its heritage and cultural background is HLLs. In this study Spanish HLLs' motivation will be discussed in relation to cultural identity.

The purpose of this exploratory thesis is to raise awareness among instructors and better support HLLs' Spanish language learning in both separate and inclusive 
environment. A secondary purpose is to promote an understanding among the Spanish HLLs themselves, since their Spanish language skills lie on an extensive spectrum. A third purpose seeks to promote this same understanding among HLLs and their peers who do not share their same heritage background. Further, this study has the potential to enhance the teachers' and students' cultural knowledge and to provide a more supportive learning environment for HLLs while provoking interest and establishing a sense of community with other students. I will achieve the above by answering the following research question: How does cultural identity influence Spanish HLLs' language learning motivation, if at all?

For the purpose of this exploration, the following definitions will be used to avoid confusion and to establish which definitions fuel this document since there exists some controversy around these topics, and their definitions, that will be discussed:

Spanish Heritage language learner (HLL): an individual who has parents from a Spanishspeaking country, but was born in the United States. These individuals have an almost comprehensive speaking proficiency and various ranges of grammatical dominance of Spanish (Valdés, 2001). This definition eliminates those students who were born in Spanish-speaking countries and those who lack proficiency in both grammatical structures and speaking ability in Spanish.

Motivation: although basic, motivation determines human behavior (Dörnyei, 1998). For the purposes of this study, motivation is the driving force that causes a HLL to pursue instruction in their heritage language, Spanish. 
Self-Determination Theory: this idea refers to the student being proactive and engaged, as opposed to being passive and alienated (Ryan \& Deci, 2000). This theory concerns students' personal and intrinsic motivation to achieve a goal rather than being concerned with external motivational factors.

Cultural Identity: the assignation that an individual gives himself or herself based on his or her connection with a particular cultural group, in this case the Latino or Hispanic culture (Valdés, 2001).

Acculturation: this term seeks to describe the "adaptive process of cultural adjustment" (Mena, Padilla, \& Maldonado, 1987, p. 207) that occurs when "two autonomous cultural groups are in constant contact" (Félix-Ortiz, Newcomb, \& Myers, 1994, p. 99).

Now that there is a basis for comparison, previous studies and current methods associated with HLLs and their instruction will be discussed. 


\section{CHAPTER II}

\section{REVIEW OF RELATED LITERATURE}

HLLs are a specialized group due to the fact that they may have previous language ability before entering a formal classroom environment. Further, being surrounded by the language of their heritage informs their social and linguistic actions in the new, formal setting (Valdés, 2001). These characteristics specific to this group of learners need to be addressed, either in the classroom or in private, to gain insight into HLLs as a whole as well as each student individually. For the purposes of this study, the social actions or experiences that HLL are introduced to in a formal setting will be discussed within the constructs of cultural identity. With cultural identity in mind, motivation will be examined. There will also be a discussion detailing the best practices to teach this specialized group and how this current state of best practices addresses cultural identity and motivation.

\section{Cultural Identity}

The way in which someone sees him or herself can greatly determine the way they behave, similar how they are motivated to complete a task (Mena et al., 1987). This concept, cultural identity, as a part of how an individual defines his or herself, can affect the way in which that person completes a task or how determined he or she is to reach a level of successful completion. Not only is there a spectrum for Spanish HLLS 
which details their cultural identity between Hispanic and North American, but also a spectrum of language ability, Spanish versus English (Valdés, 2005). This language spectrum can play a hand in how these HLLs see themselves and their cultural identity (Valdés, 2005).

Before it is possible to analyze how cultural identity and motivation intertwine, it is necessary to first discuss the overarching theme of cultural identity, as it can influence the other two components. An essential topic to cover in relation to identity, which is specific to culture, is that of acculturation. Acculturation pertains to the level in which an individual grows accustomed to and assimilates to another culture and its practices (Félix-Ortiz et al., 1994). For the purposes of this study, acculturation refers specifically to immigrants from Spanish-speaking countries coming to the United States, which ranks $29^{\text {th }}$ in the world in the number of immigrants entering its borders (Central Intelligence Agency, 2010). Another area that acculturation explores is immigrants' adjustment and development of new traditions in the new culture. Acculturation can vary depending on the generation of the individual (Félix-Ortiz et al., 1994). In many instances, with the passage of time and creation of more generations within the United States, this linguistic and cultural development becomes almost equal; that is to say, the generations shift closer to bilingualism and a more even balance between the non-native culture and native culture (Valdés, 2001). Due to acculturation and the creation of an extensive spectrum, in regard to cultural identity, it is necessary to consider bicultural and bilingual people who have varied levels of each culture that governs their lives (Félix-Ortiz et al., 1994). 
Regardless of the method and type of instruction utilized, there is a need to analyze the role of cultural identity in HLLs' language learning process. In regard to understanding the many aspects of cultural identity, Mena et al. (1987), developed a set of binary questions that serve to determine the loyalty of an individual to one culture or another; while these binary questions serve their purpose, many things have changed since the instrument was developed in 1987. The study focused on 214 multicultural college students of different generational statuses and where their cultural identity fell on the spectrum of cultural loyalty (Mena et al., 1987). Mena et al. found that the later generations were the population that contained more acculturative stress while adapting to their environment. Now, it is necessary to couple this instrument with other cultural identity viewpoints and identifiers in order to create a more accurate and cohesive understanding of the relationship between HLLs and their cultural identity.

Every individual's cultural identity encompasses a wide range and spectrum, especially in regard to HLLs. For this reason, and for the purposes of this study, a small amount of items were ranked, related to cultural identity, which are present in the instrument used. It is now necessary to discuss the relationship that occurs between the cultural identity of the individual and his or her motivation.

Motivation

Before examining the motivation that the HLLs experienced while learning a language, it is necessary to start with some more basic definitions and theories of motivation. For example, on of the most basic approaches to motivation involves 
Abraham Maslow (1943) and his hierarchy of needs that serve as motivators for individuals. The hierarchy consists of various needs starting from the bottom and most basic to the most specific and rarely achievable: physiology, safety, belongingness, self-esteem, and finally self-actualization (Maslow, 1943). Maslow (1943) said that a person could not attain the next level of the hierarchy unless the previous needs were met. In this sense, motivation is seen as building blocks that are based on essential needs for life and needs for developing as an individual.

Another view of general motivation highlights the task of goal setting and how this can promote the motivation of a task. According to Locke and Latham (1990), setting goals, especially ones that are more difficult to achieve allow for an increase in the drive and motivation of an individual to successfully complete it. There is also the issue of commitment and how that can drive an individual to strive to complete a goal. According to Locke and Latham (1990), there are three factors that contribute to successful goal completion. These include: the importance of the expected outcomes of the goal, self-efficacy or the belief that the individual has that the goal is attainable, and commitment to others that have an engagement in the goal either in its outcome or other individuals who would also need to complete that same goal (Locke \& Latham, 1990). Regardless of the type of motivation or the task that is beneficial to complete, there are many different factors and approaches to explaining this theory, some of which are more directly associated with language learning and its complexity.

The over-arching theme of motivation is a multifaceted and complex concept that can be broken down into multiple types in order to examine specific aspects of an 
individual's behavior (Dörnyei, 1998). One of these types refers to attitude and the role it has in driving an individual through completing a task. This idea refers to the intention that one possesses and how it affects that individual's behavior. This intention is deconstructed even further to expose a person's attitude towards a specific behavior as well as the subjective norm, which refers to the societal and social constraints that individuals find themselves in and how these concepts sway their behavior within society (Dörnyei, 1998). These two factors can be applied to language learning, not unlike any other subjects or areas of study, in the sense that an individual's intention will change their willingness or motivation to learn a new language.

\section{Self-Determination Theory}

Self-Determination Theory (SDT) (Ryan \& Deci, 2000) differs from motivation in the sense that it can be used to collect data to delve deeper into the reasoning that each individual student uses to justify their actions when considering natural and intrinsic motivators. In this case, the action would be choosing to study a FL. As noted above, SDT is defined as a student being proactive and relying on intrinsic motivation to drive their behavior (Ryan \& Deci, 2000). As Noels, Pelletier, Clement, and Vallerand's (2003) study outlines, it is important to validate and review both types of motivation, both intrinsic and extrinsic in order to fully establish the motivations of an individual.

According to Dörnyei (1998), SDT is one of the most general and widely recognized motivation theories and makes the distinction between intrinsic and 
extrinsic motivation. In this theory, intrinsic motivation refers to an individual completing a task or working towards a goal for the personal benefits it may entail and to become a better person for themselves. Whereas extrinsic motivation refers to an external force having some sort of influence over the behavior of an individual, causing them to work towards or complete a task. Because the concept of motivation can depend highly on intrinsic forces, it is easy to see the connection of the mind and self as its driving force. Although motivation can depend highly on intrinsic values, it is also necessary to explore the extrinsic forces at work behind the scenes that can also encourage this same motivation. Ryan \& Deci (2000) focus on this theory as more of a personality trait and a behavior itself as opposed to an individual that is driven by tangible objects.

The many factors of motivation provide for different viewpoints and personality types, but not so much that would make later instruction and data too overwhelming to put into action. SDT has a more personal connection to an individual in the sense that it mirrors a personality trait test while keeping the focus on motivation, regardless of whether it is intrinsic or extrinsic motivation (Ryan \& Deci, 2000). While SDT and the broader theories above construct a frame for motivation in general, there are more specialized theories that shape language-learning motivation specifically.

$$
\text { Motivation and Language Learning }
$$

Motivation is a key component necessary to effectively acquire or learn a FL (Dörnyei, 1998). Because motivation plays a significant role in the language learning process, it is essential to explore the meaning of language and how this meaning can 
influence the motivation and therefore the behavior of a person. Dörnyei (1998) presents three components of language that show its complexity and multiple functions: "(a) a communication coding system that can be taught as a school subject; (b) an integral part of the individual's identity involved in almost all mental activities; and also (c) the most important channel of social organisation [sic] embedded in the culture of the community where it is used" (p. 118). Before examining the link between motivation and identity, it is first beneficial to discuss language-learning motivation as a whole.

Gardner's (1985) social psychological approach to motivation explores three components: motivational intensity, desire to learn the language, and an attitude towards the act of learning the language. Through these components and Gardner's theory, it is apparent that he sees the mind as the driving force behind the overarching theme of motivation (Dörnyei, 1998).

While SDT has already been discussed, Noels et al. (2003) use it to transform it into factors to gage the language learning of their participants. Noels et al. (2003) discusses the use of SDT as a base to generate statements that are attributed to the following factors: Amotivation, External Regulation, Introjected Regulation, Identified Regulation, Intrinsic Motivation (IM) - Knowledge, IM-Accomplishment, and IMStimulation. Amotivation refers to an individual having a disinterest in acting in order to complete a task at hand (Ryan \& Deci, 2000). The following are all extrinsic factors of motivation: External Regulation consists of activities that are driven by outside forces like tangible benefits; Introjected Regulation deals with the concept of pressure that an 
individual experiences related to a certain task; Identified Regulation moves toward an individual completing a task for personal reasons (Noels et. al., 2003). The remaining factors all refer to different types of intrinsic motivation that all concern different reasons why individuals would want to accomplish a goal for themselves. For example, IM-Knowledge would refer to an individual wanting to gain knowledge and understanding of a task for themselves; IM-Accomplishment would include an individual completing a goal to feel accomplished within him or herself; IMStimulation is defined by completing a task for the fun or enjoyment of it (Noels et. al., 2003).

One subcategory of language learning motivation concerns the relationship between value, or the benefit that comes with the skill of learning a new language and an individual's expectations of what his or her skill set will be after a certain point (Dörnyei, 1998). This relationship between value and expectancy focuses on the expected success that an individual will have with the task and how highly he or she values that particular task in order to follow through with its completion (Dörnyei, 1998). Each of these components of motivation and its process is developed through different means. For example, an individual may develop his or her expectancy of success through past achievements (attribution theory), determining one's own abilities to carry out that particular task (self-efficacy theory), and making an effort to prolong a healthy self-esteem (self-worth theory) (Dörnyei, 1998). These theories, as mentioned earlier, can also apply to any task, but specifically relate to language learning here due to the probability of being motivated to learn a language through 
these theories and their meanings (Dörnyei, 1998).

One example of this extrinsic motivation that may not be traditionally thought of as an outside force is the concept of integrativeness, which may be the most important factor of motivation in language learning (Csizér \& Dörnyei, 2005). In this sense, integrativeness demonstrates the positive outlook and connection that a language learner has with the target language and culture. It also addresses how this outlook motivates the learner to persevere and be successful and motivated to thrive during the language learning process in order to master the language skills (Csizér \& Dörnyei, 2005). If this integration is the true motivation behind an individual's behavior, then it becomes a strong external driving and motivating force for an individual, as well as motivating that individual to become a global and understanding citizen.

There are many aspects and angles to the complex issue of motivation, especially when paired with language learning. One of these aspects is that of identity. Its relationship with language learning motivation will be further discussed below.

Identity and Motivation

To get a better idea of how intrinsic and extrinsic motivation and cultural identity fit together, it is beneficial to look at a group of HLLs who have what appears to be a strong heritage and cultural identity as well as to understand their motivations for learning their heritage language. Berardi-Wiltshire (2012) details a case in New Zealand of HLLS and how their cultural identity played into their motivation to learn Italian, their heritage language. Many of her participants, who were either the second or third 
generation in New Zealand, were very interested in the Italian language and motivated to learn it due to the role it played in their upbringing. As they are further removed generationally from the language than first generation immigrants who are either assimilating to the English language or trying to maintain the heritage language, it would seem as though their ties to the language would be weaker.

The topic of age is relevant here since Berardi-Wiltshire (2012) discusses a distinct age group of participants in their 30's and 40's. Some reasons her participants were highly motivated may have been because the participants were adults at the time of learning Italian and they did not have peer pressure, as well as the need to fit in with their peers like many adolescents and young adults that are college-aged do, which may have aided in their motivation (Berardi-Wiltshire, 2012). According to Dörnyei (1998) this finding may not be so uncommon because the roots of language extend deep into a person's identity, and also to the identity and cultural experiences that come with learning a new language, whether they have mastered the language or not.

Overall, this example shows that the cultural identity can have an influence on the motivation of HLLs, but there may be other factors that influence this motivation as well. These factors may include: age, generation, amount of heritage language use, as well as how these learners identify themselves within the heritage culture.

The topic of native English speakers and their motivation in language learning is also of importance for this study. One study centered on native English speakers who attended a French-English bilingual university and were currently taking French as a 
second language (Noels et al., 2003). The same criteria were used to evaluate their motivation to learn the language and contained the factors below. In the Noels et al. (2003) study, the top factors, out of seven total, were: External Regulation, Identified Regulation, and Intrinsic Motivation-Knowledge. The study focused on a group of students who's native and most used language was English and were taking psychology classes at a French-English bilingual university (Noels et al., 2003). The motivations of this group were found to be similar to the Spanish HLLs in this exploratory study.

Instructional Methods

An integral tool for instructors is their rapport with students. Valdés (2001) promotes separate classes for Spanish HLLs that are more specialized, even to the point of assigning a teacher of Hispanic descent to make students feel more at ease. Cultural understanding needs to be a top priority when instructing HLLS and having an instructor of Hispanic heritage may help Spanish HLLs be more successful in their learning.

Along with acculturation and the attempt to assimilate to a certain culture, there is a pull to maintain the heritage language and culture, despite the Englishspeaking surroundings (Valdés, 2001). The instructional methods and environment are vital when discussing this linguistic and cultural maintenance and how this target group of students can maintain a connection with their heritage. Valdés et al. (2008) discuss how to maintain the heritage language and focus on the topics surrounding recent issues with teaching HLLs, along with HLLs' instructional concerns. They detail 
the controversy surrounding adding specific classes centered around Spanish HLLs and their needs, suggesting a more personal approach to teaching Spanish HLLs. This more personal approach to heritage language learning, it is thought, will provoke interest by HLLs in a class that may only be for a credit. It may also have the ability to transform the class to encourage the desire to learn the written language, grammar, and speaking elements of Spanish on part of the Spanish HLLs (Valdés et al., 2008).

Considering the many needs of any diverse group of students, in this case HLLs, must involve finding a way to assess and include these needs in instruction. This means having not only the whole class in mind, but also the individual as a separate category. It is vital that these assessments and other assignments take into consideration the cultural identity of the individual, as well as the class culture in order to be optimal for development and understanding between students and cultures. Valdés et al. (2001) describe the direct instruction provided to HLLs in the FL classroom, as well as the methods employed to teach HLLs. These methods mainly rely on communication skills, if they are in a classroom with students of any level or solely grammar, if they are in a secluded group of only HLLs. Because of the wide range of levels among HLLs, it is necessary to have more well-rounded instruction to meet everyone's needs, regardless of the classroom type.

Valdés et al. (2005) call for action towards more inclusive instruction and for language learners to consider bilingualism the ultimate goal, instead of non-HLLs learning Spanish and Spanish HLLs learning English. Bilingualism is an integral part of today's society and reading and writing skills are vital for the working world (Félix-Ortiz 
et al., 1994). Because the native language's register is usually familial, it is necessary to develop all parts of the language in order to give the speakers a well-rounded language that is useful in multiple registers (Valdés, 2001). Valdés et al. (2001) hint towards a need for separated and specialized instruction for these students instead of ways to include them in a class with non-HLLs; however, applying the same messages and techniques in a classroom that is not specialized for HLLs can still have significant benefits for all students. Those messages may include goals or activities that promote the understanding of a wide array of cultures and practices within different groups to encourage as well as maintain a close-knit group of global citizens within a student population.

Effective classroom activities should connect different types of learners and provide a diverse classroom that has the ability to meet different types of students' needs (Edstrom, 2006). These activities while encouraging learning and providing a reasonable level of challenge and success, keep students from getting too frustrated with new material. Edstrom (2006) employs narrative writing to explain and discuss various ideas related to cultural identity of HLLs through their target language. Edstrom addresses a wider scope of students, regardless of any differences, because there is something to be gained, whether it is linguistically or culturally, if a teacher has HLLs in their class or not. Her approach bridges the gap between groups and touches on the best common practices that can generally be applied to any FL classroom. These activities also reach other students, HLLs or non-HLLs that can demonstrate how the language is viewed by their peers. 


\section{Conclusion}

Second language acquisition research can be better applied to HLLs by drawing on bilingualism research that gives insight into this group of students (Valdés, 2005). The SLA field should be expanded to include the group of HLLs and recognize their particular language learning needs. Valdés (2005) argues that in order to maintain a more globalized and culturally accepting population, Spanish HLLs must have a strongly accessible community connected to the Spanish language.

For optimal student success in a HLL or FL classroom, instructors must understand the cultural identities of all students and how they influence students' motivation to learn the language. By helping HLLs to develop areas they need more support with and perfect areas that they already have certain dominance over it is possible to make HLLs more successful in the language classroom. 


\section{CHAPTER III}

\section{METHODOLOGY}

\section{Participants}

Participants are undergraduate Spanish HLLs who have had instruction in a college-level Spanish classroom, either separate from non-HLL students or in a setting that includes many different types of students and abilities. Participants are 22 college-aged HLLs who attend a mid-sized university in the Midwest. They come from different heritage backgrounds in regard to countries of origin: fifteen from Mexico, one from Guatemala, and one from Puerto Rico, but all were born in the United States to parents who were born in a Spanish-speaking country.

\section{Materials}

Participant consent was gained through an introductory page to an online survey (see Appendix A). Participants could choose which part(s) they wanted to participate in since the study includes an online means of data collection.

The first means of data collection is a loyalty scale for participants and parents, adapted from Mena eta al. (1987) and consisting of 21 items plus optional comments, if they chose to provide them, that serve as an indicator of participant cultural identity (see Appendix B). This instrument gathers information about the linguistic and social preferences of the participants by asking them to choose between Hispanic or North 
American, Spanish or English, and asks a yes or no question that detail these situations where one culture is preferred and therefore seen as the dominant culture within the participants.

The second means of data collection examines motivational levels and was informed by Noels et al. (2003). I utilized their factors to determine participants' motives for language learning: Amotivation, External Regulation, Introjected Regulation, Identified Regulation, Intrinsic Motivation - Knowledge, Intrinsic Motivation-Accomplishment, and Intrinsic Motivation-Stimulation (see Appendix C). Participants indicated to what extent they thought the statements were true or false. Participants indicated their degree of agreement with each of the 20 statements using a Likert scale that included Strongly Agree (coded as 4), Agree (3), Disagree (2), and Strongly Disagree (1). Three of the 20 items were coded differently, Strongly Agree (1), Agree (2), Disagree (3), and Strongly Disagree (4) due to the negative phrasing of the sentence on which the options are based. Participants could also provide additional comments in the space provided.

Procedures

My study consists of quantitative data. I first emailed the SelectSurvey survey link to students currently enrolled or previously enrolled in a class for HLLs offered at their home campus. As a secondary source for finding suitable participants, I sent my definition of a HLL to Spanish professors via email and asked them to identify Spanish HLLs in their class and send me an email with those students' names. I also asked these same professors to mention my study in their classes, highlighting the definition 
of HLLs, to encourage students to self-identify as HLLs and to contact me directly. For some context, I used frequency counts to detail the linguistic and general social preferences of the HLLs. I also used frequency counts to show the frequency of each of the motivation statements across the participants and the factors of motivation themselves. To compare both cultural identity and motivation together, I used the self-identification that the participants used for their cultural identity, Hispanic versus North American, and compared them with the means of motivation factors that were chosen for each group.

Standard deviation for the participants and their motivational factors were used to show a relationship between the factors, as well as the groups of HLLs that identified as Hispanic and those who identified as North American participants. 


\section{CHAPTER IV}

\section{RESULTS}

This study answers this research question: How does cultural identity influence language-learning motivation in HLLs, if at all? I analyzed the cultural loyalty of the participants as a whole. To begin, I determined main ethnic groups that the participants have contact with and which groups they prefer to interact with and in what situations. As can be seen in Table 1, there was an almost even split among the participants in regard to the ethnic background of their closest friend, while the majority of their friends are Caucasian. When asked with whom they prefer to socialize, the majority of participants said both Hispanic and Caucasian groups and only three to four participants chose either/or depending on the item. Four participants indicated that they socialized with members of all ethnic groups, as opposed to only limiting their social groups to Caucasian, Hispanic, or both. In the final item that I used, participants were asked to indicate which ethnic background they prefer to be romantically involved with: Caucasian, Hispanic, both, or other. The responses to this category were much more evenly distributed.

Table 1 represents items that serve to gauge the cultural identity and overall background information of this group and shows the situations in which the heritage culture is preserved, by being selected. Also, it shows where the heritage culture is 
abandoned, or when the opposite of the heritage culture it is selected.

Table 1. Interaction between Participants and Peers

\begin{tabular}{|c|c|c|c|c|}
\hline $\begin{array}{c}\text { Question: } \\
\text { Ethnic group: }\end{array}$ & $\begin{array}{c}\text { Closet } \\
\text { friend }(f)\end{array}$ & $\begin{array}{c}\text { Majority of } \\
\text { good friends } \\
(f)\end{array}$ & $\begin{array}{c}\text { Socialize with } \\
(f)\end{array}$ & Date $(f)$ \\
\hline Hispanic & 11 & 5 & 3 & 6 \\
\hline Caucasian & 10 & 16 & 3 & 7 \\
\hline Both & 0 & 0 & 13 & 6 \\
\hline Other & 2 & 2 & 4 & 4 \\
\hline
\end{tabular}

To further assess participants' background information and social situations,

Figure 1 shows the responses to other questions adapted from Mena et al.'s (1987) Loyalty Scale. Four questions were asked in regard to cultural identity: Would you be offended if someone were to insult the U.S.? Would you be offended if someone were to insult Americans? Would you prefer to date people of the same culture? Would you prefer to marry within your same culture? The answers to all four of these questions were almost exactly even in every situation. For question 1 , Would you be offended if someone were to insult the U.S.?, 11 responded with "yes" and 12 "no." For question 2, Would you be offended if someone were to insult Americans?, 13 responded "yes" and 10 "no." Continuing, for, question 3, Would you prefer to date people of the same culture?, 11 said "yes" and 12 "no." Finally, for question 4, Would you prefer to marry within your same culture?, 12 said "yes" and 11 "no." The data show that just as many participants answered "yes" as those who answered "no" to each question. 


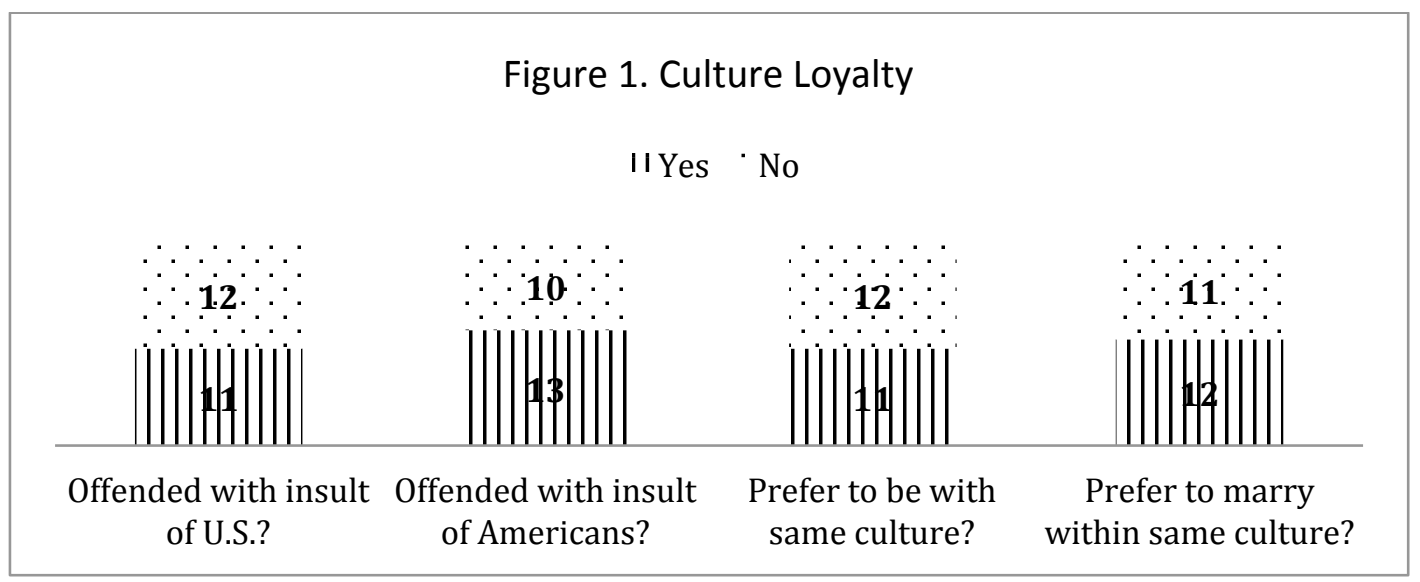

As mentioned by Valdés (2008), HLLs have different registers in which they use different languages; these registers and situations are described below and through the following tables. This language use is separated in the tables below by registers. Table 2 details the language that is used between the participants and their peers. There are different situations in which speech would come up. For example, language the participant uses when speaking with his or her closest friend, language his or her closest friend uses when speaking to the participant, and language spoken by the majority of the participants' friends. The first situation, in Table 2, concerns the language spoken where the participant lives.

With the exception of this first situation, English tended to be the dominant language spoken among different friend groups. For example, among the languages spoken between each participant and their closest friends, was English with 16, followed by 7 who responded that both languages were spoken and none said that Spanish was the dominant language. The language spoken by the majority of the participants' friends was almost completely dominated by English, with the exception 
of 2 participants that said both languages were used, and again Spanish was not present. The unique item, where language in the home is examined, showed the most variance: English chosen by 8 participants, Spanish chosen by 2, and 12 that selected both languages.

Table 2. Peer Language

\begin{tabular}{|c|c|c|c|}
\hline $\begin{array}{c}\text { Language: } \\
\text { Situation: }\end{array}$ & English $(f)$ & Spanish $(f)$ & Both $(f)$ \\
\hline $\begin{array}{c}\text { Language spoken } \\
\text { where you live }\end{array}$ & 8 & 2 & 72 \\
\hline $\begin{array}{c}\text { Language you } \\
\text { speak to closest } \\
\text { friend }\end{array}$ & 16 & 0 & 7 \\
\hline $\begin{array}{c}\text { Language she/he } \\
\text { speaks to you }\end{array}$ & 21 & 0 & 2 \\
\hline $\begin{array}{c}\text { Language spoken } \\
\text { by majority of } \\
\text { friends }\end{array}$ & & & 7 \\
\hline
\end{tabular}

Table 3 represents the language spoken by participants in various familial contexts within the family structure. It details the language that the mother uses with her spouse, children, and friends and also the language the father uses with his spouse, children, and friends. For example, between the mother and father, four responded with the use of both languages, six responded with English, and thirteen with Spanish. Between the mother and her children, four responded with the use of both languages, six responded with English, and twelve for Spanish. Between the mother and her friends, four responded with the use of both languages, six responded with English, and thirteen with Spanish. As for the father's tendencies, between the father and mother, five responded with the use of both languages, six 
responded with English, and thirteen with Spanish. Between the mother and her friends, four responded with the use of both languages, six responded with English, and thirteen with Spanish. As for the father's tendencies, between the father and mother, five responded with the use of both languages, six responded with English, and thirteen with Spanish. Between father and his children, six responded with the use of both languages, eight responded with English, and nine with Spanish. Finally, between father and his friends, five responded with the use of both languages, eight responded with English, and ten with Spanish. In all cases, Spanish was the dominant language that is spoken in the familial register. The language of the father was slightly more evenly distributed in regard to the use of English, Spanish or both languages.

Table 3. Family Language

\begin{tabular}{|c|c|c|c|}
\hline $\begin{array}{c}\text { Language: } \\
\text { Situation: }\end{array}$ & English $(f)$ & Spanish $(f)$ & Both $(f)$ \\
\hline Mother to father & 6 & 13 & 4 \\
\hline Mother to her children & 6 & 12 & 4 \\
\hline Mother to her friends & 6 & 13 & 4 \\
\hline Father to mother & 6 & 12 & 5 \\
\hline Father to children & 8 & 9 & 6 \\
\hline Father to his friends & 8 & 10 & 5 \\
\hline
\end{tabular}

Table 4 shows the degrees of participant agreement with statements about their motivation for learning Spanish, as adapted from Noels et al. (2003). It shows the following factors: Amotivation, External Regulation, Introjected Regulation, Identified Regulation, IM-Knowledge, IM-Accomplishment, and IM-Stimulation. In Table 4 below, using the frequency counts from the Likert scale items pertaining to 
motivation, each factor is divided into its items and the degrees of agreement: Strongly Agree (coded as 4), Agree (3), Disagree (2), Strongly Disagree (1), are shown. Total participant responses indicated the strongest agreement with Identified Regulation, IM-Knowledge, and IM-Accomplishment.

How each participant identified him or herself was also examined. Participants chose to identify themselves as either North American or Hispanic, with specification for country of origin, and each individual chose their rankings for the Likert scale items addressing motivation. As detailed, Table 5 shows those who identified themselves as North American and Table 6 shows those who identified themselves as Hispanic. Each table shows the frequency counts of the motivational factors that each group of participants identified most with regarding their heritage language learning. 
Table 4. Frequency of Each Item with Degrees of Agreement

\begin{tabular}{|c|c|c|c|c|}
\hline Factors/Degree of agreement & SD (4) & $\mathrm{D}(3)$ & $\mathrm{A}(2)$ & SA (1) \\
\hline 18. Because I truly have the impression of wasting my time in studying a second language & 17 & 4 & 1 & 0 \\
\hline 19. Because I can't come to understand what I am doing by studying a second language & 14 & 4 & 4 & 0 \\
\hline 20. Because I do not care about studying a second language & 16 & 3 & 1 & 1 \\
\hline \multicolumn{5}{|l|}{ Amotivation } \\
\hline Factors/Degree of agreement & SD (1) & $\mathrm{D}(2)$ & A (3) & SA (4) \\
\hline 3. Because I have the impression that it is expected of me & 7 & 7 & 3 & 6 \\
\hline 4. In order to get a more prestigious job later on & 1 & 2 & 9 & 11 \\
\hline 17. In order to have a better salary later on & 2 & 2 & 7 & 11 \\
\hline \multicolumn{5}{|l|}{ External Regulation } \\
\hline 5. Because I would guilty if I didn't know a second language & 7 & 10 & 3 & 3 \\
\hline 6. To show myself that I am a good citizen because I can speak a second language & 5 & 6 & 9 & 3 \\
\hline $\begin{array}{l}\text { 9. Because I would feel ashamed if I couldn't speak to my friends from the second language community in their } \\
\text { native tongue }\end{array}$ & 6 & 5 & 5 & 5 \\
\hline \multicolumn{5}{|l|}{ Introjected Regulation } \\
\hline 1. Because I choose to be the kind of person who can speak a second language & 1 & 2 & 8 & 12 \\
\hline 8. Because I think it is good for my personal development & 0 & 0 & 13 & 10 \\
\hline \multicolumn{5}{|l|}{ Identified Regulation } \\
\hline 10. For the pleasure that I experience in knowing more about the literature of the second language group & 2 & 2 & 9 & 9 \\
\hline 12. For the satisfied feeling I get in finding out new things & 2 & 1 & 10 & 9 \\
\hline $\begin{array}{l}\text { 13. Because I enjoy the feeling of acquiring knowledge about the second language community and their way of } \\
\text { life }\end{array}$ & 1 & 0 & 9 & 12 \\
\hline \multicolumn{5}{|l|}{ IM-Knowledge } \\
\hline 7. For the enjoyment I experience when I grasp a difficult concept in the second language & 2 & 2 & 10 & 9 \\
\hline 14. For the pleasure I experience when surpassing myself in my second language studies & 2 & 1 & 12 & 7 \\
\hline 15. For the satisfaction I feel when I am in the process of accomplishing difficult exercises in the second language & 1 & 3 & 12 & 6 \\
\hline \multicolumn{5}{|l|}{ IM-Accomplishment } \\
\hline 2. For the pleasure I get from hearing the second language spoken by native second language speakers & 4 & 3 & 9 & 7 \\
\hline 11.For the "high" feeling that I experience while speaking in the second language & 5 & 7 & 6 & 4 \\
\hline 16. For the "high" I feel when hearing foreign languages spoken & 5 & 5 & 6 & 6 \\
\hline IM-Stimulation & & & & \\
\hline
\end{tabular}


Table 5. Frequency of Each Item with Degree of Agreement for North American Participants

\begin{tabular}{|c|c|c|c|c|}
\hline Factors/Degree of agreement & SD (4) & $\mathrm{D}(3)$ & $A(2)$ & SA (1) \\
\hline 18. Because I truly have the impression of wasting my time in studying a second language & 5 & 0 & 0 & 0 \\
\hline 19. Because I can't come to understand what I am doing by studying a second language & 4 & 1 & 0 & 0 \\
\hline 20. Because I do not care about studying a second language & 5 & 0 & 0 & 0 \\
\hline \multicolumn{5}{|l|}{ Amotivation } \\
\hline Factors/Degree of agreement & SD (1) & $\mathrm{D}(2)$ & A (3) & SA (4) \\
\hline 3. Because I have the impression that it is expected of me & 2 & 3 & 0 & 0 \\
\hline 4. In order to get a more prestigious job later on & 0 & 1 & 3 & 1 \\
\hline 17. In order to have a better salary later on & 0 & 1 & 3 & 1 \\
\hline \multicolumn{5}{|l|}{ External Regulation } \\
\hline 5. Because I would guilty if I didn't know a second language & 1 & 2 & 1 & 1 \\
\hline 6. To show myself that I am a good citizen because I can speak a second language & 1 & 2 & 2 & 0 \\
\hline $\begin{array}{l}\text { 9. Because I would feel ashamed if I couldn't speak to my friends from the second language community in } \\
\text { their native tongue }\end{array}$ & 3 & 1 & 0 & 0 \\
\hline \multicolumn{5}{|l|}{ Introjected Regulation } \\
\hline 1. Because I choose to be the kind of person who can speak a second language & 0 & 1 & 2 & 2 \\
\hline 8. Because I think it is good for my personal development & 0 & 0 & 3 & 2 \\
\hline \multicolumn{5}{|l|}{ Identified Regulation } \\
\hline 10. For the pleasure that I experience in knowing more about the literature of the second language group & 0 & 1 & 3 & 1 \\
\hline 12. For the satisfied feeling I get in finding out new things & 0 & 0 & 4 & 1 \\
\hline $\begin{array}{l}\text { 13. Because I enjoy the feeling of acquiring knowledge about the second language community and their } \\
\text { way of life }\end{array}$ & 0 & 0 & 3 & 2 \\
\hline \multicolumn{5}{|l|}{ IM-Knowledge } \\
\hline 7. For the enjoyment I experience when I grasp a difficult concept in the second language & 0 & 0 & 3 & 2 \\
\hline 14. For the pleasure I experience when surpassing myself in my second language studies & 0 & 0 & 4 & 1 \\
\hline $\begin{array}{l}\text { 15. For the satisfaction I feel when I am in the process of accomplishing difficult exercises in the second } \\
\text { language }\end{array}$ & 0 & 1 & 4 & 0 \\
\hline \multicolumn{5}{|l|}{ IM-Accomplishment } \\
\hline 2. For the pleasure I get from hearing the second language spoken by native second language speakers & 0 & 2 & 2 & 1 \\
\hline 11.For the "high" feeling that I experience while speaking in the second language & 2 & 2 & 1 & 0 \\
\hline 16. For the "high" I feel when hearing foreign languages spoken & 2 & 3 & 0 & 0 \\
\hline IM-Stimulation & & & & \\
\hline
\end{tabular}


Table 6. Frequency of Each Item with Degree of Agreement for Hispanic Participants

\begin{tabular}{|c|c|c|c|c|}
\hline Factors/Degree of agreement & SD (4) & $\mathrm{D}(3)$ & $A(2)$ & SA (1) \\
\hline 18. Because I truly have the impression of wasting my time in studying a second language & 12 & 4 & 1 & 0 \\
\hline 19. Because I can't come to understand what I am doing by studying a second language & 10 & 3 & 4 & 0 \\
\hline 20. Because I do not care about studying a second language & 11 & 3 & 1 & 1 \\
\hline \multicolumn{5}{|l|}{ Amotivation } \\
\hline Factors/Degree of agreement & SD (1) & $\mathrm{D}(2)$ & A (3) & SA (4) \\
\hline 3. Because I have the impression that it is expected of me & 5 & 4 & 3 & 6 \\
\hline 4. In order to get a more prestigious job later on & 1 & 1 & 6 & 10 \\
\hline 17. In order to have a better salary later on & 2 & 1 & 4 & 10 \\
\hline \multicolumn{5}{|l|}{ External Regulation } \\
\hline 5. Because I would guilty if I didn't know a second language & 6 & 8 & 2 & 2 \\
\hline 6. To show myself that I am a good citizen because I can speak a second language & 4 & 4 & 7 & 3 \\
\hline $\begin{array}{l}\text { 9. Because I would feel ashamed if I couldn't speak to my friends from the second language community in } \\
\text { their native tongue }\end{array}$ & 3 & 4 & 5 & 5 \\
\hline \multicolumn{5}{|l|}{ Introjected Regulation } \\
\hline 1. Because I choose to be the kind of person who can speak a second language & 1 & 1 & 6 & 10 \\
\hline 8. Because I think it is good for my personal development & 0 & 0 & 10 & 8 \\
\hline \multicolumn{5}{|l|}{ Identified Regulation } \\
\hline 10. For the pleasure that I experience in knowing more about the literature of the second language group & 2 & 1 & 6 & 8 \\
\hline 12. For the satisfied feeling I get in finding out new things & 2 & 1 & 6 & 8 \\
\hline $\begin{array}{l}\text { 13. Because I enjoy the feeling of acquiring knowledge about the second language community and their way } \\
\text { of life }\end{array}$ & 1 & 0 & 6 & 10 \\
\hline \multicolumn{5}{|l|}{ IM-Knowledge } \\
\hline 7. For the enjoyment I experience when I grasp a difficult concept in the second language & 2 & 2 & 7 & 7 \\
\hline 14. For the pleasure I experience when surpassing myself in my second language studies & 2 & 1 & 8 & 6 \\
\hline $\begin{array}{l}\text { 15. For the satisfaction I feel when I am in the process of accomplishing difficult exercises in the second } \\
\text { language }\end{array}$ & 1 & 2 & 8 & 6 \\
\hline \multicolumn{5}{|l|}{ IM-Accomplishment } \\
\hline 2. For the pleasure I get from hearing the second language spoken by native second language speakers & 4 & 1 & 7 & 6 \\
\hline 11.For the "high" feeling that I experience while speaking in the second language & 3 & 5 & 5 & 4 \\
\hline 16. For the "high" I feel when hearing foreign languages spoken & 3 & 2 & 6 & 6 \\
\hline IM-Stimulation & & & & \\
\hline
\end{tabular}


As can be seen in Table 5, items 7, 8, 12, 13, 14 were more commonly answered as either Agree or Strongly Agree by the participants that identified themselves as North American. Table 6 shows that item 8 was the highest rated item with items 1 and 4 close behind as the leading items of motivation. While the factors in general may be similar, when broken down to the item level, there is some variance as noted above.

Table 7. Descriptive Statistics of Self-identified Groups by Motivational Factors

\begin{tabular}{|lr|l|l|}
\hline & & Hispanic (16) & \multicolumn{1}{|c|}{$\begin{array}{l}\text { North } \\
\text { American (5) }\end{array}$} \\
\hline Amotivation: & Mean: & 3.47 & 3.93 \\
& SD: & .73 & .15 \\
\hline ER & Mean: & 3.10 & 2.53 \\
& SD: & .79 & .51 \\
\hline IntroR & Mean: & 2.38 & 2.14 \\
& SD: & .91 & .38 \\
\hline IdentR & Mean: & 3.41 & 3.3 \\
& SD: & .58 & .57 \\
\hline IM-K & Mean: & 3.23 & 3.2 \\
& SD: & .87 & .38 \\
\hline IM-A & Mean: & 3.02 & 3.13 \\
& SD: & .89 & .18 \\
\hline IM-S & Mean: & 2.67 & 2.13 \\
& SD: & 1.04 & .77 \\
\hline
\end{tabular}

Table 7 shows the factors and their means and standard deviation based on the item responses for each factor. Table 7 is also divided between those who self-identified as North American and Hispanic. As can be seen, the most agreeable factor for Hispanic participants appears to be Amotivation, but this may be difficult because of the negative 
manner in which the item was worded. Amotivation shows the lack of motivation a person has, which appeared to be the most disagreeable factor among both groups, although the means are higher. The factor that is second most agreeable for Hispanic participants is Identified Regulation; for North American participants, the second highest is Identified Regulation as well. Table 5 shows the factors of motivation for these two groups to be very similar.

Once again throughout all of the results and charts we are reminded of how complex and deep the issue of motivation is, especially in regard to one's cultural identity. 


\section{CHAPTER V}

\section{DISCUSSION}

At the beginning of this study, I theorized that cultural identity would have a significant influence in HLLs studying Spanish, but I found that this was not the case. It seemed as though many participants did have connections to their culture and identified themselves with that culture across various topics, such as familial language, the group of friends they have, and most specifically in the ethnic group they assign themselves to, but other items in the survey were answered in a fashion that provided doubt as to whether the participants were completely loyal to one culture over another. For example, there were instances when a participant identified him or herself as Hispanic, but noted that they would be offended by insults made to either the U.S. or Americans. There were also participants who identified themselves as North American, but stated that they would be offended by these insults towards the U.S. or Americans. There were areas in which they did not side with their culture only, since it was always an option to choose both ethnic groups. The almost even split between offense taken in regard to U.S. or American insults, as well as between what group is preferential for socializing with or dating, shown in Figure 1, demonstrates how divided the participants can be in their own cultural identity. The strongest tie to their cultural identity and main base for the comparison between motivation and cultural identity is the self- 
identification of the participants as either Hispanic or North American.

Although cultural ties among participants are present, their motivation did not show their cultural identity as the driving factor to learn Spanish. For example, the top three factors that were most prevalent among the participants were also prevalent factors found in Noels et al. (2003) for native speakers of English learning French. As can be seen above, the top three factors of motivation according to this group of participants are: Identified Regulation, IM-Knowledge, and IM-Accomplishment. In the Noels et al. (2003) study, the top factors were: External Regulation, Identified Regulation, and IM-Knowledge. This is especially surprising because the group of native English speakers does not consist of HLLs of French and therefore does not have a high influence of cultural identity toward the French culture necessarily. There were other factors that I expected them to choose based on the cultural implications in the statements. For example, in the category of External Regulation there is a response that has the participant rank the following statement: "Because I have the impression that it is expected of me" (Noels et al., 2003). The reason I had expected participants to rank this statement and factor higher is the relationship that it has towards feeling obligated to learn the language based on their heritage. These feelings of obligation can influence the feelings that an individual has towards their heritage language (Valdés, 2001). I also expected the average for the Introjected Regulation statements to be higher because it contained options such as, "Because I would feel ashamed if I couldn't speak to my friends from the second language community in their native tongue" and "Because I would feel guilty if I didn't know a 
second language" (Noels et al., 2003). Again, for the same ties that these responses have to the feelings that a HLL experiences towards their heritage language, I expected the statements in this factor to have a higher average than what was seen. One area that I did expect to be a higher average was IM-Knowledge, specifically the item stating, "Because I enjoy the feeling of acquiring knowledge about the second language community and their way of life" (Noels et al., 2003). This factor did average higher than others for my participants. Upon viewing the individualized results for my participants, based solely on the aforementioned statements in External Regulation, Introjected Regulation and IM-Knowledge, it can be observed that those participants who identified themselves as Hispanic, thus having some sort of identity connection to their heritage culture, did have a higher rate of either agreeing or strongly agreeing with the statements that were anticipated with this group of Spanish HLL participants. Alternatively, those individuals who identified themselves as North American lacked any responses in two of the expected statements, items 6 and 9 . In conclusion, with regard to motivation, two of the statements that I expected to be more prevalent among Spanish HLLs alone were present and the other two were also present in those Spanish HLLs that identify with the North American culture.

With their age in mind, the participants also may not consider the need or desire to have a strong connection with their culture. Although the participants in my study self-identified as Hispanic, there were many who had varying opinions on who they socialize with or date, a factor that could show signs of a diminishing connection to their heritage culture. The age of the participants in Berardi-Wiltshire (2013) were much 
older and sometimes second and even third generation immigrants who desired to learn Italian in a formal setting because of the culture that they had been removed from. The participants in my study were normally the first generation born in the United States and the second generation to live in the United States, and as such may have experienced much more closeness to their heritage instead of distance like the participants in the Berardi-Wiltshire (2013).

The majority of this study's participants spoke English with friends and Spanish with family. This is relevant again, due to the age group of my participants because they are dependent on their peers' perceptions of them and may choose to identify more with their friend group and the language that they use more often, especially being on a university campus and near more peers than family members.

Overall, the depth and complexity of both cultural identity and motivation can be seen in detail throughout this study and through its results. 


\section{CHAPTER VI}

\section{CONCLUSIONS AND RECOMMENDATIONS}

In conclusion, my exploratory study has shed some light on a profound topic: Spanish HLLs. Although there are many improvements that can be made to make this study more effective as an indicative tool into the pedagogical practices in regards to HLLs, for its purposes here, it has succeeded in providing a brief insight into the cultural identity of this group of Spanish HLLs and their motivation for learning Spanish.

Some aspects that can be changed going forward deal with the tools that were used to serve as marker for the cultural identity of the participants. The tool used by Mena et al. (1987) was adapted to use more modern terms, but through some of the selections it was obvious that there was a need for a new tool. One example of this is shown in the effects that insults to the U.S. or Americans would have on the participants. The idea is that if the person would feel insulted, then they identify more with the American culture instead of the Hispanic culture, but this may not always be the case. It does not account for personal feelings; that is to say that someone who is either American or Hispanic may not be insulted by these comments toward Americans or the U.S., not because they do not culturally identify with these groups, but perhaps because they remain indifferent on the subject. 
There are several ideas for future studies that relate to motivation or cultural identity. In the future it would always be more beneficial to have more participants. Another step that could be helpful is examining the participants on an individual basis for each section of the study to see if their heritage only affects certain topics. In this study the main findings were all based on the participants as a whole and how they saw themselves in general in addition to where their motivations to study Spanish generally came from instead of individually breaking each participant's answers into their own data sets. There are also aspects of this study that could be explored further, such as the influence, if at all, of gender on the participants' feelings toward cultural identity and even motivation. Another topic that would be interesting to explore would be age and how it influences, if at all, the cultural identity, specifically in terms of motivation. This is due to the fact that the Berardi-Wiltshire (2013) study had a more diverse group of individuals in comparison to this one. Because of the difference in generation shown in the Berardi-Wiltshire (2013) study and the specialized age group in my study, it may be possible for future studies to relate generations who are living or born in a foreign country and how that location influences cultural identity and by association motivation to learn the heritage language, if at all.

There are many ways in which this study could be improved. First, as mentioned previously, I recommend that it be replicated with a larger number of participants to better demonstrate the connections between cultural identity and motivation. Secondly, a more detailed instrument, and even an interview component to better assess the cultural identity of an individual, would yield a more accurate representation 
of the actual level of each participant's cultural identity instead of assessing the group as a whole on an outdated scale. Another avenue to explore in future research could be to include where each participant would rank on the spectrum of HLLs and how this influences that person's cultural identity and motivation, if at all.

While this study provides a snapshot into the growing need for FL teachers to understand Spanish HLLs and how to teach them Spanish, there is still more work to be done. Cultural identity still remains an area in need of study so that productive, inclusive learning environments can be available for all students learning Spanish. 


\section{REFERENCES}

Berardi-Wiltshire, A. (2012). Reframing the foreign language classroom to accommodate the heritage language learner: A study of heritage identity and language learning motivation. New Zealand Studies In Applied Linguistics, 18 (2), 21-34.

Castillo, J. M. (2003). Teaching Spanish to heritage speakers: Issues of language and identity. Geolinguistics, 29, 51-57.

Central Intelligence Agency. (2010). United States. The world factbook. Retrieved from https://www.cia.gov/library/publications/the-worldfactbook/geos/us.html

Csizér, K., \& Dörnyei, Z. (2005). The Internal Structure of Language Learning Motivation and Its Relationahip with Language Choice and Leanring Effort. The Modern Language Journal, (1), 19-36.

Dörnyei, Z. (1998). Motivation in second and foreign language learning. Language Teaching, 31(3), 117-135.

Edstrom, A. (2006). Oral narratives in the language classroom: A bridge between nonnative, heritage, and native-speaking learners. Hispania, 89(2), 336-346.

Félix-Ortiz, M., Newcomb, M. D., \& Myers, H. (1994). A multidimensional measure of cultural identity for Latino and Latina adolescents. Hispanic Journal of Behavioral Sciences, 16(2), 99-115.

Gardner, R. C. (1985). Social psychology and second language learning: The role of attitudes and motivation. London: Edward Arnold.

Locke, E. A., \& Latham, G. P. (1990). A theory of goal setting \& task performance. Prentice-Hall, Inc.

Maslow, A. H. (1943). A theory of human motivation. Psychological review, 50(4), 370-396.

Mena, F. J., Padilla, A. M., \& Maldonado, M. (1987). Acculturative stress and specific coping strategies among immigrant and later generation college students. Hispanic Journal of Behavioral Sciences, 9(2), 207-225.

Noels, K., Pelletier, L., Clement, R., \& Vallerand, R. (2003). Why are you learning a second language? Motivational orientations and self-determination theory. Language Learning, 53 33-63.

Ryan, R., \& Deci, E. (2000). Self-determination theory and the facilitations of intrinsic motivation, social development, and well-being. American Psychologist, 59(1), 68-78.

The Nuffield Foundation. (2000). Languages: The next generation - The final report and recommendations of the Nuffield Languages Inquiry. London: Author. 
Retrieved from http://education.staffordshire.gov.uk/NR/rdonlyres/5125DF6822FC-4C1A-A719-C46FAD567EB0/57676/nuffieldlanguages_finalreport.pdf

Valdés, G. (2001). Heritage language students: Profiles and possibilities. In J. K. Peyton, D. A. Ranard, \& S. McGinnis (Eds.), Heritage Languages in America, 3777. Arlington, VA: Center for Applied Linguistics.

Valdés, G. (2005). Bilingualism, heritage language learners, and SLA research: Opportunities lost or seized? The Modern Language Journal, 89(3), 410-426.

Valdés, G., Fishman, J. A., Chávez, R., \& Perez, W. (2008). Maintaining Spanish in the United States: Steps toward the effective practice of heritage language re- acquisition/development. Hispania, 91(1), 4-24. 
APPENDIX A

INFORMED CONSENT (FOR SURVEY)

\begin{abstract}
PLEASE READ THIS DOCUMENT CAREFULLY. CLICK TO CONTINUE BELOW ONLY IF YOU AGREE TO PARTICIPATE AND YOU FULLY UNDERSTAND YOUR RIGHTS. YOU MUST BE 18 YEARS OF AGE TO GIVE YOUR CONSENT TO PARTICIPATE IN RESEARCH. IF YOU DESIRE A COPY OF THIS CONSENT FORM, YOU MAY PRINT THIS FORM.
\end{abstract}

The policy of the Department of Languages, Literatures and Cultures at Illinois State University is that all research participation is voluntary, and you have the right to withdraw at any time, without prejudice, should you object to the nature of the research. Your responses are anonymous. Any report of the data collected will be in summary form, without identifying individuals. You are entitled to ask questions and to receive an explanation after your participation. If you decide now or at any point to withdraw this consent or stop participating, you are free to do so at no penalty to yourself. You are free to skip specific questions and continue participating at no penalty.

This research study looks at the language background of Spanish heritage speakers. In the following survey you will be asked to answer questions about your experience with the Spanish language and your personal background. I may want to disseminate samples of the responses to other researchers, educators, students, or anyone interested in them with the understanding that the participant's name will never be disclosed nor used. In the cases where examples or data are shared with other researchers, educators and/or students the condition will be that they cannot further analyze the data nor use it for further research purposes.

If you choose not to give me permission to use examples of your responses for presentations or teaching but you agree to participate, I will use the data collected but will not share samples of responses for presentations or teaching.

Some possible risks to you involve that you may feel that any failure in performance can be made available to future potential employers or teachers/professors. However, all data will be kept secure and destroyed once analysis has been finished. Also, I will not in any way discuss or disseminate results of this study to any current or future employers or teachers/professors. In addition, you may feel distress if you think you did not perform well but I am only interested in learning about your 
language background.

Although there may be no direct benefit to you, the possible benefit of your participation is that you may reflect on your own language background and cultural identity. If interested, you may contact me to find out about the results of this analysis.

If you have concerns about your participation in this study, you may contact: Lydia Reitz (Isreitz@ilstu.edu) Phone: (309) 532- 5686

Any questions regarding your rights as a research participant or research-related injuries may be directed the Office of Research, Ethics, and Compliance Office at Illinois State University at (309) 438-2529.

I have read the statements above, understand the same, and voluntarily participate in this survey. I further acknowledge that I can print a copy of this consent form for my records if I so desire.

(By clicking yes, you are also stating that you are 18 years of age or older.) LINK "YES" TO SURVEY DEPLOY LINK

Yes No (I am not 18 or I choose not to participate) 


\section{APPENDIX B \\ LOYALTY SCALE FOR PARTICIPANTS AND PARENTS}

(adapted from Mena et al., 1987)

\section{Participants}

1. What is the ethnic background of your closest friend?

Hispanic Other (Specify)

2. What is the ethnic background of the majority of your good friends?

Hispanic Other (Specify)

3. Who do you prefer to socialize with?

Hispanic Other (Specify)

4. What ethnic group members do you prefer to date? Hispanic Other (Specify)

5. How would you identify yourself? Hispanic (specify country or countries) Other (Specify)

6. If someone were to insult the U.S., would you feel offended? Yes No

7. If someone were to insult Americans, would you feel offended? Yes No

8. Do you prefer to be with those who are from the same culture? Yes No

9. Would you prefer to eventually marry a person of your own ethnic origin? Yes No

10. In what language(s) do you speak to your closest friend? Spanish Other (Specify) 
11. In what language(s) does she/he speak to you?

Spanish Other (Specify)

12. In what language(s) do you speak to the majority of your friends? Spanish Other (Specify)

13. What language(s) is/are often spoken where you live? Spanish Other (Specify)

\section{Parents}

1. What is the ethnic background of most of your parents' friends? Hispanic Other (Specify)

2. What language does your mother use to speak to your father? Spanish Other (Specify)

3. What language does your mother use to speak to her children? Spanish Other (Specify)

4. What language does your mother use to speak to her friends? Spanish Other (Specify)

5. What language does your father use to speak to your mother? Spanish Other (Specify)

6. What language does your father use to speak to his children? Spanish Other (Specify)

7. What language does your father use to speak to his friends? Spanish Other (Specify)

8. Do your parents watch television programs in a non-English language? Yes (specify) No

9. Please use the space below to say anything about your ethnic, cultural, or linguistic heritage. 


\section{APPENDIX C \\ SELF-DETERMINATION IDENTIFICATION SURVEY \\ (adapted from Noels, et al., 2000)}

Please circle the number that most describes your feelings towards the following statements using the scale listed below.

1

Strongly Disagree
2

Disagree
3

Agree
4

\section{Strongly Agree}

I study a language...

1. Because I choose to be the kind of person who can speak a second language.

1 2

3

4

2. For the pleasure I get from hearing the second language spoken by native second language speakers.

1 2

3

4

3. Because I have the impression that it is expected of me.

1 2 3

4

4. In order to get a more prestigious job later on.

1 2

3

4

5. Because I would feel guilty if I didn't know a second language.

1 2 3

4

6. To show myself that I am a good citizen because I can speak a second language. 1 2 3 4

7. For the enjoyment I experience when I grasp a difficult concept in the second language. 
1

Strongly Disagree
2

Disagree
3

Agree
4

Strongly Agree

8. Because I think it is good for my personal development.

1 2

3

4

9. Because I would feel ashamed if I couldn't speak to my friends from the second language community in their native tongue.

1 2 3

4

10. For the pleasure that I experience in knowing more about the literature of the second language group.

$\begin{array}{llll}2 & 3 & 4\end{array}$

11. For the "high" feeling that I experience while speaking in the second language. 1 2 3 4

12. For the satisfied feeling I get in finding out new things. 1 2 3 4

13. Because I enjoy the feeling of acquiring knowledge about the second language community and their way of life.

$\begin{array}{llll}1 & 2 & 3 & 4\end{array}$

14. For the pleasure I experience when surpassing myself in my second language studies.

1 2

3

4

15. For the satisfaction I feel when I am in the process of accomplishing difficult exercises in the second language.

1 2

3

4

16. For the "high" I feel when hearing foreign languages spoken. 1 2 3

17. In order to have a better salary later on. 
1

Strongly Disagree
2

Disagree
3

Agree
4

Strongly Agree

I do not want to continue studying a language...

1. Because I truly have the impression of wasting my time in studying a second language.

1

3

4

2. Because I can't come to understand what I am doing by studying a second language.

1 2

3

4

3. Because I do not care about studying a second language.

1

2

3

4

4. Please use the space below to say anything more about you motivation to learn Spanish. 